\title{
Thermal and Dielectric Properties of Cyanate Ester Cured Main Chain Rigid-Rod Epoxy Resin
}

\author{
Chi-Ping $\mathrm{Li}^{1, * \mathbb{D}}$ and Chih-Min Chuang ${ }^{2}$ \\ 1 Department of Chemical Engineering, National United University, Miaoli 36063, Taiwan \\ 2 Institute of Nuclear Energy Research, Longtan, Taoyaun 32546, Taiwan; cmchuang@iner.gov.tw \\ * Correspondence: chipingli@nuu.edu.tw
}

Citation: Li, C.-P.; Chuang, C.-M Thermal and Dielectric Properties of Cyanate Ester Cured Main Chain Rigid-Rod Epoxy Resin. Polymers 2021, 13, 2917. https://doi.org/ $10.3390 /$ polym 13172917

Academic Editor: Yu-Wei Su

Received: 10 August 2021

Accepted: 28 August 2021

Published: 30 August 2021

Publisher's Note: MDPI stays neutral with regard to jurisdictional claims in published maps and institutional affiliations.

Copyright: (c) 2021 by the authors. Licensee MDPI, Basel, Switzerland. This article is an open access article distributed under the terms and conditions of the Creative Commons Attribution (CC BY) license (https:// creativecommons.org/licenses/by/ $4.0 /)$.

\begin{abstract}
Thermal and dielectric properties of rigid-rod bifunctional epoxy resin 4,4-bis(2,3-epoxypropoxy) biphenyl epoxy (BP) and commercial epoxy resin diglycidyl ether of bisphenol A (DGEBA) were studied using differential scanning calorimeter (DSC), thermogravimetric analyzer (TGA), dynamic mechanical analyzer (DMA), thermal mechanical analyzer (TMA) and dielectric analyzer (DEA). These two epoxies were cured with cyanate ester hardener 2,2'-bis(4-cyanatophenyl) propane (AroCy B10). The BP/B10 system consisting of a rigid-rod structure exhibited better thermal properties than the DGEBA/B10 system with a flexible structure. Anisotropic BP/B10 (2:1) had the highest 5\% weight loss temperature, the highest amount of residue and a smaller thermal expansion coefficient than the commercial DGEBA/B10 system. The BP/B10 system, which cured at the LC phase temperature, had higher Tg than the commercial DGEBA/B10 system, as found from dynamic mechanical analysis. The BP/B10 system also demonstrated better dielectric properties than the commercial DGEBA/B10 system when enough curing agent was provided.
\end{abstract}

Keywords: epoxy resin; liquid crystal; cyanate esters; thermal properties; dielectric properties

\section{Introduction}

Epoxies (EP) have been widely used in industrial applications, such as for coatings, adhesives, composite materials, electronic components, etc., due to their excellent characteristics such as easy processing, high mechanical strength, low shrinkage, resistance to chemical solvents, heat resistance, adhesion and good electrical insulation [1-10]. DGEBA is the most studied epoxy resin that has been widely used in various industrial applications, such as paints, coatings and adhesive applications, due to its good mechanical and thermal properties, low curing shrinkage and good chemical resistance. Another reason for the popularity of DGEBA is its low cost. However, there are some serious drawbacks, such as brittleness or low fracture energy, significantly restricting its extensive utilization [11,12]. Other epoxies, consisting of an aromatic rigid-rod backbone structure, are well-known to exhibit outstanding thermal and mechanical properties. A great deal of these types of epoxies also have liquid crystal (LC) behavior [13,14]. Rigid-rod thermoset epoxies have been synthesized for use as encapsulation materials because of their good performance. Some of them retain the LC behavior after being cured with the curing agent [15-17]. Su et al. synthesized an epoxy (BP) using biphenol mesogens and epichlorohydrin that displayed high glass transition temperature, low thermal expansion coefficients, high dielectric strengths and low dielectric loss after curing $[13,18,19]$. Su et al. showed that $\mathrm{BP} /$ sulfanilamide (SAA) displayed LC phase after curing, which resulted in high glass transition temperature and a low thermal expansion coefficient [20].

Cyanate ester (CE) resins possess excellent dielectric properties, thermal resistance and good flame-retardancy [21-26]. CE belong to a family of monomers with cyanate end groups $(-\mathrm{O}-\mathrm{C} \equiv \mathrm{N}-)$ which provide good thermal degradation temperature due to forming an aryl cyanurate network through a trimerization reaction. The mechanism of the 
cyanate ester reacting with epoxy first produces the alkyl cyanurate, and alkyl isocyanurate is formed after rearrangement, then cycle oxalolidinone is formed after reacting with epoxy [27-29]. Those high-performance EP/CE resins can be used in electronic packaging encapsulants and printed circuit boards due to their great thermal and dielectric properties [30-35]. Krishnadevi and Selvaraj used DGEBA/B10 combined with flame-retardant and functionalized rice husk ash, which showed good dielectric properties and thermal stability [36]. Wu et al. integrated tetra methyl biphenyl epoxy (TMBP) with B10, which also exhibited great dielectric properties and thermal stability [37]. Ariraman et al. presented a combination of DGEBA/CE and terminated polydimethylsiloxane to obtain a thermally stable and low dielectric constant material [38]. Yu et al. added liquid crystalline epoxy resin into DGEBA/B10, which demonstrated an improvement of glass transition temperature, thermal expansion coefficient and mechanical properties [39]. Liang et al. demonstrated that lower molecular weight EP in the DGEBA/CE system had better thermal, moisture absorption and mechanical properties [40]. Wu et al. reported that DGEBA/B10 mixed with glutaric anhydride (GA) and zinc (II) acetylacetonate (ZAA) exhibited high initial thermal decomposition temperatures of $337-353^{\circ} \mathrm{C}$. The EP/CE/GA/ZAA system had thermal selfhealing behavior resulting from the transesterification and possible reactions between the residual cyanate ester and epoxy groups, and a $78-83 \%$ fracture toughness recovery of the hybrid can be achieved after the first healing rate of $200{ }^{\circ} \mathrm{C} / 2 \mathrm{~h}$ [41]. Wang et al. declared that diglycidyl ether of bisphenol F (DGEBF)/B10 mixed with phenolphthalein poly(ether sulfone) displayed higher fracture toughness and impact strength [42]. Wang et al. highlighted that the glass transition temperature, thermal stability and moisture absorption were found to increase with the epoxy functionality when naphthalene-containing epoxy resins were cured with B10 [43]. Ho et al. pronounced that DGEBA and 2-(6-oxido-6Hdibenz(c,e)(1,2)-oxaphosphorin-6-yl)-1,4-benzenediol (DOPOBQ) cured with various CE exhibited higher glass transition temperatures, better dimensional stability and better thermal stability [44].

Our previous work [45] studied the BP/B10 system but did not look at the details of the curing process and try to keep the LC (anisotropic) phase after curing. In this research, liquid crystalline $\mathrm{EP}$ (BP) was cured using CE (B10) as a curing agent and formed anisotropic phase in the materials. The thermal and dielectric properties of the $\mathrm{BP} / \mathrm{B} 10$ and DGEBA/B10 systems were investigated in this research. The novelty and significance of this work is to study how to maintain the LC phase in the cured epoxy resin using CE as a curing agent and to study the improvement of the thermal and dielectric properties. Few studies keep LC phase in epoxy through applying CE. The methodology of this research uses DSC, TGA, DMA and TMA to perform the thermal analysis. The DEA was used to carry out the dielectric analysis.

\section{Materials and Methods}

\subsection{Materials}

The BP with an epoxy equivalent weight of 180 was synthesized according to previous literature [18]. The DGEBA was obtained from Dow Chemical Company (Midland, MI, USA) with an epoxy equivalent weight of 185.3. The curing agent B10 was purchased from CibaGeigy (Tokyo, Japan). The structures of the epoxy resin and curing agent are shown in Figure 1. The catalyst copper(II) acetylacetonate was purchased from Aldrich (St. Louis, MO, USA). 


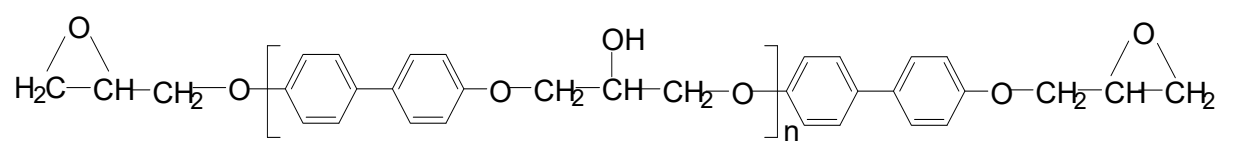

4,4'-bis(2,3-epoxypropoxy)biphenyl (BP)

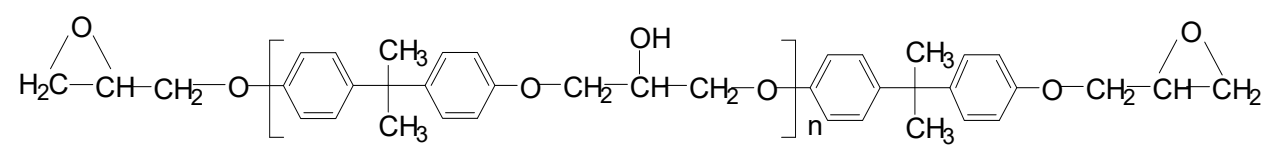

Diglycidyl ether of bisphenol A (DGEBA)

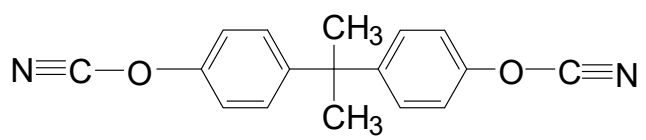

2,2'-bis(4-cyanatophenyl)propane (B10)

Figure 1. The chemical structures of epoxy resins (BP and DGEBA) and the curing agent (B10).

\subsection{Preparation of Cured Epoxy}

One TA instrument, DSC-10, was used to determine the curing conditions of the $\mathrm{EP} / \mathrm{CE}$ system. This experiment uses different epoxy resins (BP and DGEBA) and a curing agent (B10) in different ratios (2:1 and 1:1), and $0.1 \%$ of the total weight of the catalyst, copper(II) acetylacetonate, which was grounded before adding to the epoxy resin. The mixture was heated to $130{ }^{\circ} \mathrm{C}$ to melt and then stirred. After the mixture was mixed well, it was poured into a preheated mold for the curing reaction.

\subsubsection{DGEBA/B10 System}

The required equivalents of the epoxy resin (DGEBA) and the cyanate ester curing agent (B10) were precisely weighed. Then, $0.1 \%$ of the total weight of the catalyst was mixed with B10, ground with a grindstone, then the epoxy resin was added and heated up to $130^{\circ} \mathrm{C}$. After the sample was completely melted, the mixture was stirred thoroughly and poured into the preheated mold. The curing condition was as follows: curing at $130{ }^{\circ} \mathrm{C}$ for $6 \mathrm{~h}$, at $175^{\circ} \mathrm{C}$ for $6 \mathrm{~h}$ and then at $200{ }^{\circ} \mathrm{C}$ for $6 \mathrm{~h}$, all at a heating rate of $10^{\circ} \mathrm{C}$ per minute when raising the temperature.

\subsubsection{BP/B10 System}

The mixing method was the same as above. The curing condition of normal BP/B10 (2:1) was: curing at $130^{\circ} \mathrm{C}$ for $6 \mathrm{~h}$, at $150^{\circ} \mathrm{C}$ for $6 \mathrm{~h}$, at $175^{\circ} \mathrm{C}$ for $6 \mathrm{~h}$ and at $200^{\circ} \mathrm{C}$ for $6 \mathrm{~h}$, all at a heating rate of $10^{\circ} \mathrm{C}$ per minute when raising the temperature. In order to preserve the anisotropic properties in the BP/B10 (2:1) system after curing, the curing condition occurred under vacuum and curing at a temperature $\left(150^{\circ} \mathrm{C}\right)$ where $\mathrm{BP}$ is at a $\mathrm{LC}$ phase for $16 \mathrm{~h}$. Then, the temperature was increased to $220^{\circ} \mathrm{C}$ at a heating rate of $1{ }^{\circ} \mathrm{C}$ per minute to cure for $6 \mathrm{~h}$. This BP/B10 (2:1) is addressed as anisotropic BP/B10 (2:1). The BP/B10 (1:1) had the same curing condition.

\subsection{Morphological Observation of the Epoxy Resin}

The BP/B10 mixture was placed on a hot plate. A polarized optical microscope (POM, NIKON, ECLIPSE ME600, Tokyo, Japan) and a V8 camera were used to observe and record the morphology changes of the sample during different curing processes.

\subsection{XRD Measurement}

The X-ray diffraction measurement was obtained from a Rigaku D/Max-VIII instrument at $2^{\circ} / \mathrm{min}, 3$ to $30^{\circ}$, at $40 \mathrm{KV}, 30 \mathrm{~mA}$. 


\subsection{Thermal Properties}

The TA instrument DSC $-10\left(5^{\circ} \mathrm{C} / \mathrm{min}\right.$ in $\left.50 \mathrm{~mL} / \mathrm{min} \mathrm{N}_{2}\right)$ was used to determine the $\mathrm{Tg}$ of the cured resins. The Du Pont TGA 951 thermal gravimetric analyzer (TGA) $\left(10^{\circ} \mathrm{C} / \mathrm{min}\right.$ in $50 \mathrm{~mL} / \mathrm{min} \mathrm{N}_{2}$ ) was used to study the weight loss with increasing temperature. The Du Pont $9900983 \mathrm{DMA}\left(5^{\circ} \mathrm{C} / \mathrm{min}\right.$ in air, $1 \mathrm{~Hz}, 20 \mu \mathrm{m}$ amplitude) was used to identify the change in modulus and damping properties. The TA instrument TMA $2940\left(10^{\circ} \mathrm{C} / \mathrm{min}\right.$ in air) was used to measure the coefficient of thermal expansion.

\subsection{Dielectric Properties}

The TA instrument DEA $2970\left(10,100,1000\right.$ and 10,000 Hz, in $50 \mathrm{~mL} / \mathrm{min}_{2}$ ) was used to study the dielectric properties of cured epoxy resins.

\section{Results and Discussion}

\subsection{Morphological Observation}

Figure 2a shows that the BP/B10 (2:1) mixture was cured on a hot plate at a constant temperature of $150^{\circ} \mathrm{C}$ for $1 \mathrm{~h}$, and the resulting anisotropic morphology was observed with a polarizing microscope $(\mathrm{POM})$. Figure $2 \mathrm{~b}$ shows that the mixture was cured at a constant temperature of $150^{\circ} \mathrm{C}$ for $5 \mathrm{~h}$ and anisotropic textures were formed. Figure $2 \mathrm{c}$ shows the configuration after being cured at $150{ }^{\circ} \mathrm{C}$ for $5 \mathrm{~h}$ and then heated to $210{ }^{\circ} \mathrm{C}$ at a rate of $10^{\circ} \mathrm{C} / \mathrm{min}$. In the figure, each grid of the scale is $10 \mu \mathrm{m}$.

Figure $2 \mathrm{~d}$ shows that the BP/B10 (2:1) mixture was cured on a hot plate at $160{ }^{\circ} \mathrm{C}$ for $1 \mathrm{~h}$, and the resulting morphology was observed with a POM. Figure 2e shows that the mixture was cured at $160^{\circ} \mathrm{C}$ for $5 \mathrm{~h}$ at a constant temperature, and its anisotropic texture is also shown here. Figure $2 \mathrm{f}$ shows the texture after being cured at $160{ }^{\circ} \mathrm{C}$ for $5 \mathrm{~h}$ and then heated to $210{ }^{\circ} \mathrm{C}$ at a rate of $10^{\circ} \mathrm{C} / \mathrm{min}$. The LC phase grew in certain directions and evolved an anisotropic crystallization. The formation of micro-sized LC phase with fibrous anisotropic texture showing crystalline morphology of BP cured with a curing agent can also be seen in our previous work [46].

The observation results showed that a constant temperature of $150^{\circ} \mathrm{C}$ produces optical anisotropic texture within a few minutes, while a constant temperature of $160^{\circ} \mathrm{C}$ produces optical anisotropic texture in about an hour. The textures of the two were different. At a constant temperature of $160^{\circ} \mathrm{C}$, it was spherical and had a filamentous structure. The domain generated at a constant temperature of $150{ }^{\circ} \mathrm{C}$ was much denser than that at a constant temperature of $160{ }^{\circ} \mathrm{C}$. Combining this result and the DSC data [18] that BP exhibits LC phase at $150{ }^{\circ} \mathrm{C}$, the curing condition at the first stage which can maintain LC phase was $150^{\circ} \mathrm{C}$.

(a)

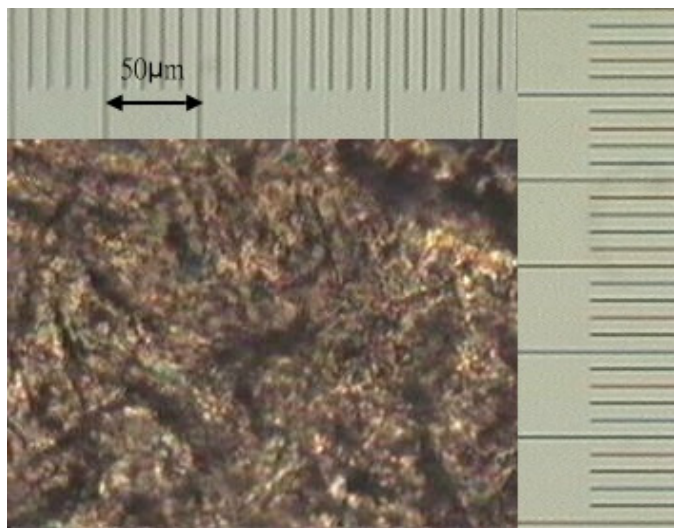

(b)

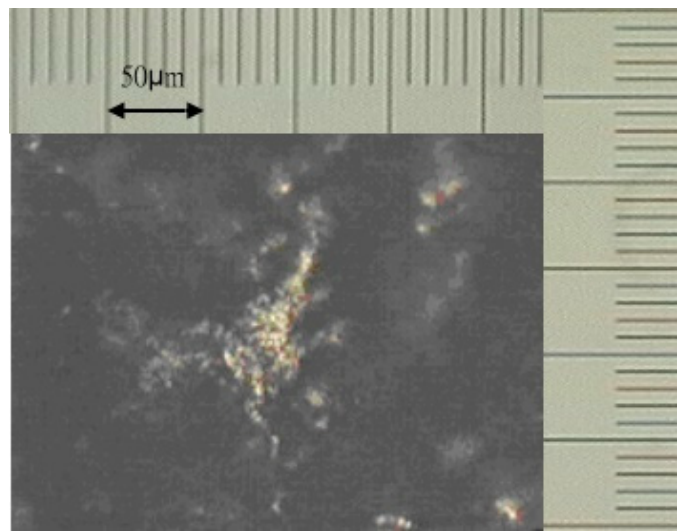

Figure 2. Cont. 
(c)

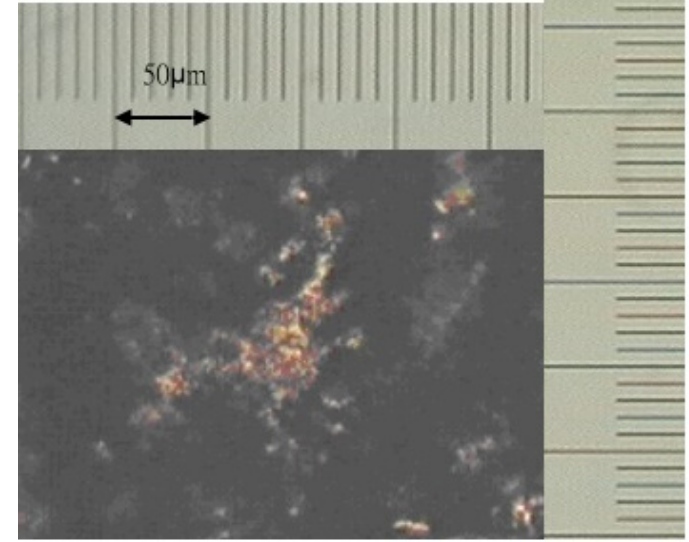

(e)

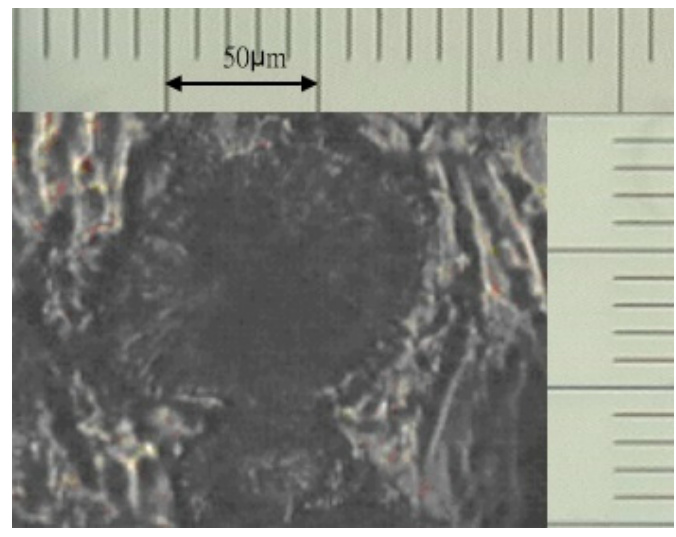

(d)

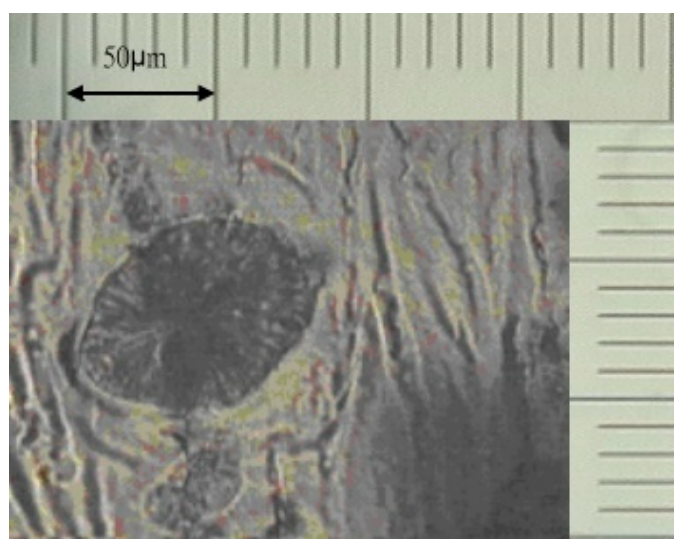

(f)

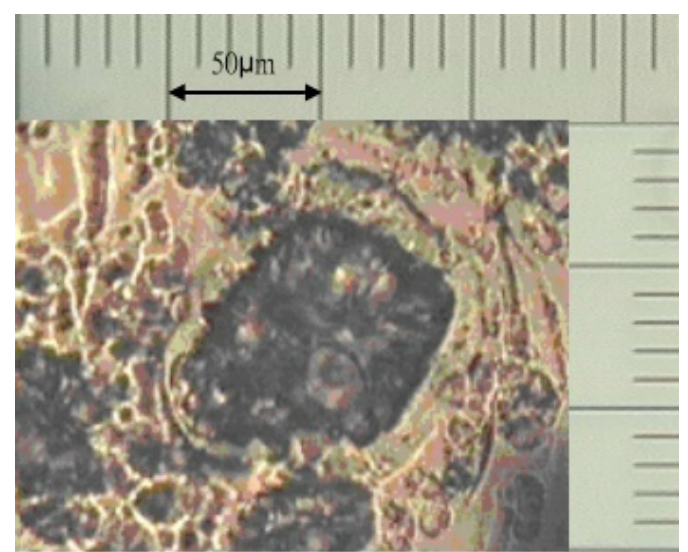

Figure 2. Polarized optical microscope (POM) image of (a) BP/B10 (2:1) $150^{\circ} \mathrm{C} / 1 \mathrm{~h}, 200 \times$. (b) $\mathrm{BP} / \mathrm{B} 10(2: 1) 150{ }^{\circ} \mathrm{C} / 5 \mathrm{~h}$, $200 \times$. (c) BP/B10 $(2: 1) 150{ }^{\circ} \mathrm{C} / 5 \mathrm{~h}$, ramp $10{ }^{\circ} \mathrm{C} / \mathrm{min}$ to $210^{\circ} \mathrm{C}, 200 \times$. (d) BP/B10 (2:1) $160{ }^{\circ} \mathrm{C} / 1 \mathrm{~h}, 500 \times$. (e) $\mathrm{BP} / \mathrm{B} 10(2: 1)$ $160{ }^{\circ} \mathrm{C} / 5 \mathrm{~h}, 500 \times$. (f) $\mathrm{BP} / \mathrm{B} 10(2: 1) 160{ }^{\circ} \mathrm{C} / 5 \mathrm{~h}$, ramp $10^{\circ} \mathrm{C} / \mathrm{min}$ to $210^{\circ} \mathrm{C}, 500 \times$.

\subsection{XRD Analysis}

By using DSC and polarized microscopy, we observed a smectic LC phase in the range of $128-153^{\circ} \mathrm{C}$ for BP epoxy [20]. The anisotropic BP/B10 (2:1) sample exhibited partially opaque features, and BP/B10 (1:1) showed much less opaque but not clear features. The BP/B10 (2:1) showed less clear features. The opaque features indicated that there was a crystalline structure in the anisotropic BP/B10 (2:1). The X-ray analysis was used to examine the crystalline phase of the BP/B10 system. Anisotropic BP/B10 (2:1) had a crystalline structure, as shown in Figure 3 . The sharp diffraction peak at $2 \theta=3^{\circ}$, and $\mathrm{d}$ spacing is equal to $29.4 \AA$. Another broad diffraction peak at $2 \theta=16-24^{\circ}$, and d spacing is equal to 4-5 $\AA$. Our previous work [20] demonstrated that smectic structure is preserved in the BP/SAA system, with the same broad peak in the XRD, which indicated that anisotropic $\mathrm{BP} / \mathrm{B} 10$ (2:1) had smectic phase. The X-ray diffraction peak indicating smectic LC phase can also be observed in the literature [47]. The highly ordered structure of the anisotropic BP/B10 (2:1) system may be responsible for the good thermal stability and lowest CTE value of all samples. 


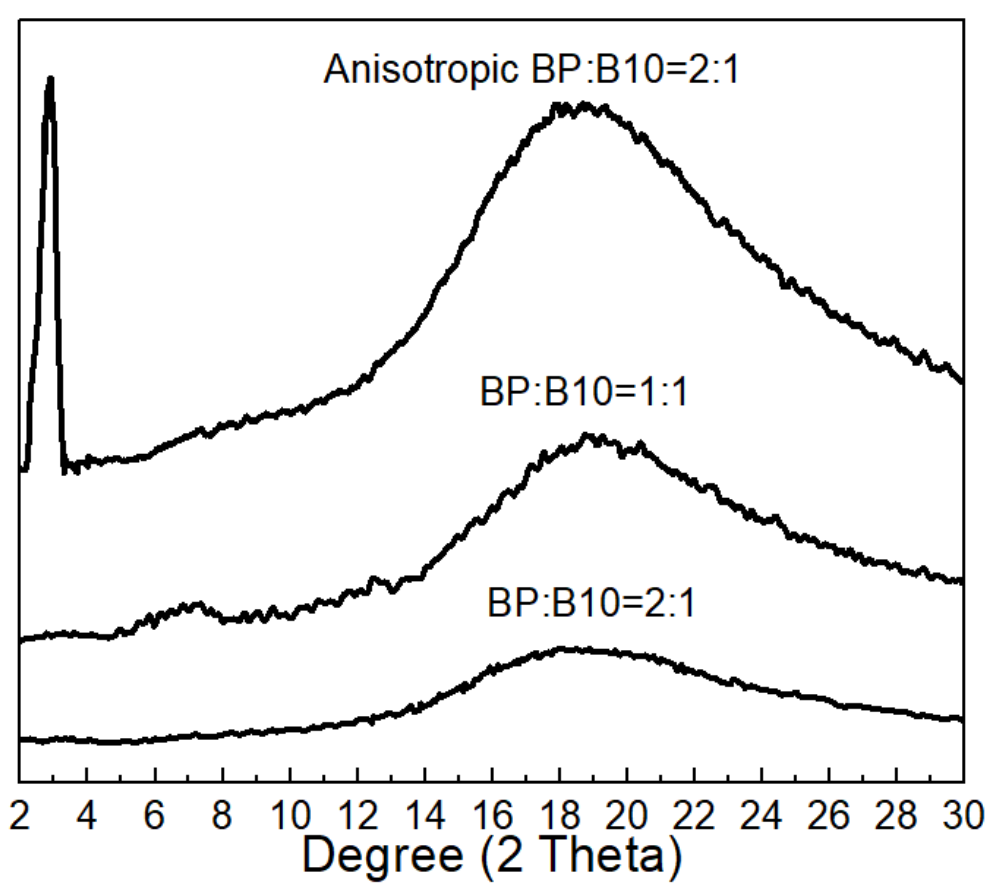

Figure 3. X-ray diffraction patterns of cured rigid-rod epoxy resins.

\subsection{TGA Analysis}

The TGA scanning curves were measured at a heating rate of $10{ }^{\circ} \mathrm{C} /$ min under $\mathrm{N}_{2}$. In the TGA plot, the beginning temperature of decomposition (the temperature at which the weight loss reaches $5 \%$ ) and the char yield at $350,400,450$ and $500{ }^{\circ} \mathrm{C}$ were obtained. The plots were used to differentiate the temperature, and thus the fastest decomposition rate and the fastest decomposition rate temperature were obtained.

As seen from Table 1 and Figure $4 \mathrm{a}$, the temperature of $5 \%$ weight loss of anisotropic BP/B10 (2:1) was the highest, and the amount of decomposition residue was also the highest. This is because of the LC structure in the anisotropic sample and the enhanced thermal stability. The sample of BP/B10 (2:1) had the lowest temperature of 5\% weight loss. Although the $5 \%$ weight loss temperature of DGEBA/B10 (2:1) was higher than that of $\mathrm{BP} / \mathrm{B} 10(2: 1)$, the amount of decomposition residue was the lowest at 450 and $500{ }^{\circ} \mathrm{C}$. This is due to the flexible structure of DGEBA, which can easily crosslink and formed a denser network than the normal BP sample after curing, and it displayed high thermal stability at the beginning of high temperatures, but it decomposed fast and retained fewer residues after reaching a higher temperature because it does not have a rigid-rod structure. Those phenomena agree with our previous research [45]. The temperature of 5\% weight loss of anisotropic BP/B10 (2:1) was $15{ }^{\circ} \mathrm{C}$ higher than the anisotropic BP/DDS (1:1) system [46], although anisotropic BP/DDS (1:1) had a higher curing temperature and formed LC phase much easier. This may be because BP/B10 (2:1) was cured at LC temperature for a long time to fix the LC phase, and was thus not easy to crack. The amount of decomposition residue in BP/B10 (1:1) was higher than that of DGEBA/B10 (1:1). This BP had more rigid-rod molecules than DGEBA. The fastest decomposition rate of DGEBA/B10 (1:1) was the largest due to a lack of rigid-rod chains. 
Table 1. 5\% weight loss temperature and residual weight of cyanate ester-cured epoxy resin.

\begin{tabular}{|c|c|c|c|c|c|c|}
\hline \multirow{2}{*}{ Cured Epoxy } & \multirow{2}{*}{ Epoxy:B10 Ratio } & \multirow{2}{*}{$5 \%$ Weight Loss Temp $\left({ }^{\circ} \mathrm{C}\right)$} & \multicolumn{4}{|c|}{ Residual Weight (\%) } \\
\hline & & & At $350^{\circ} \mathrm{C}$ & At $400{ }^{\circ} \mathrm{C}$ & At $450^{\circ} \mathrm{C}$ & At $500{ }^{\circ} \mathrm{C}$ \\
\hline $\mathrm{BP} *$ & \multirow{3}{*}{$2: 1$} & 362.7 & 96.65 & 79.85 & 45.26 & 40.30 \\
\hline $\mathrm{BP}$ & & 304.4 & 74.62 & 46.48 & 28.77 & 26.49 \\
\hline DGEBA & & 344.3 & 94.31 & 65.62 & 16.80 & 14.86 \\
\hline $\mathrm{BP}$ & \multirow{2}{*}{$1: 1$} & 335.1 & 92.35 & 62.53 & 42.77 & 38.96 \\
\hline DGEBA & & 344.7 & 94.21 & 60.13 & 34.40 & 21.23 \\
\hline
\end{tabular}
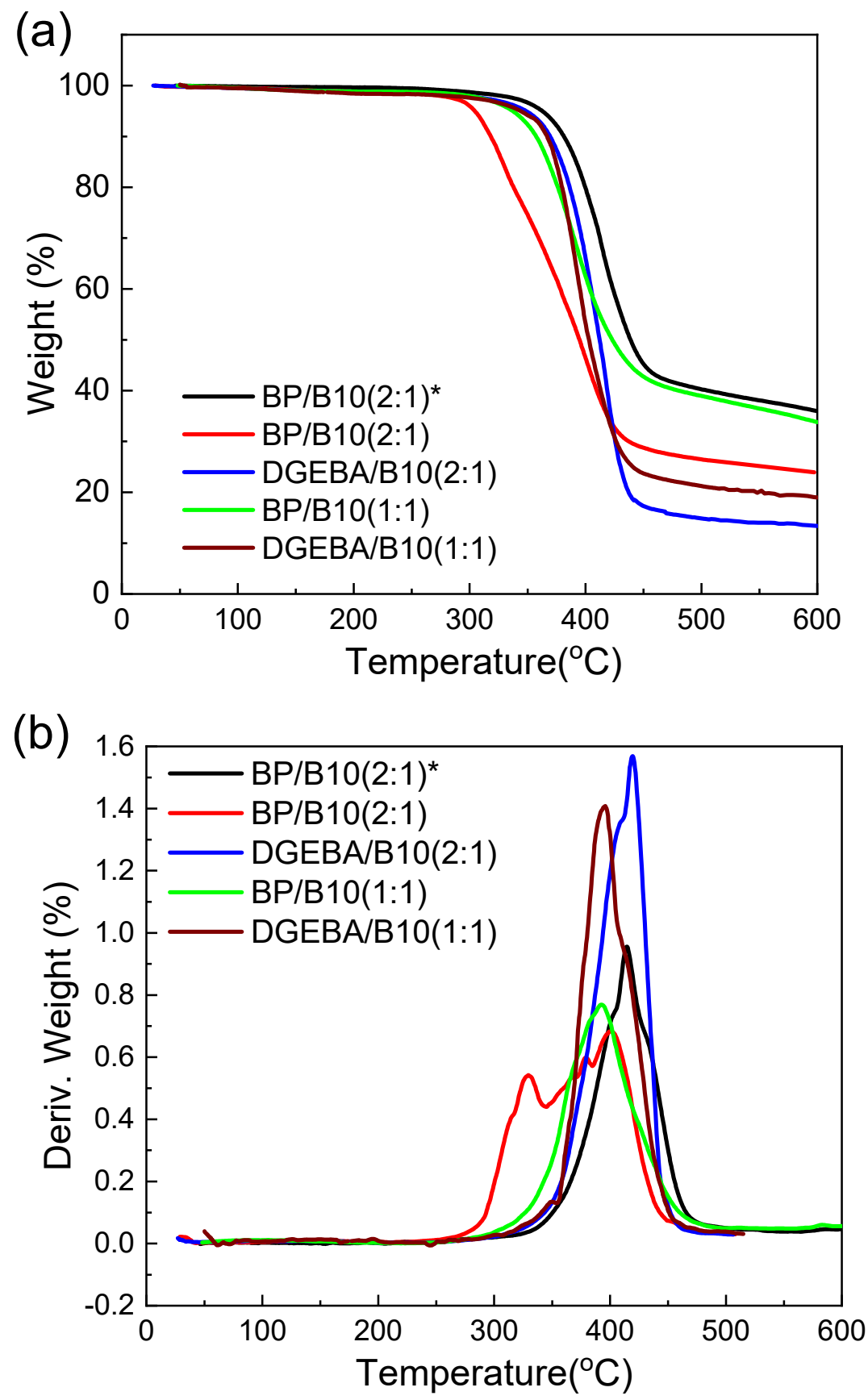

Figure 4. (a) Thermogravimetric analysis of cyanate ester (B10)-cured epoxy resin, (b) derivative weight versus temperatures of B10-cured epoxy resin $\left({ }^{*}\right.$ : anisotropic). 
From Table 2, anisotropic BP/B10 (2:1) had the highest and fastest decomposition rate temperature because of the existence of LC phase, and DGEBA/B10 (2:1) had the highest and fastest decomposition rate due to flexible main chains of DGEBA. Figure $4 \mathrm{~b}$ shows that anisotropic BP/B10 (2:1) and BP/B10 (2:1) had two-stage decomposition, which may be from the decomposition of two portions in the sample, such as linear epoxy resin and cyanate ester network structure. This may be because the curing agent was not enough, and more uncured linear portions existed in BP/B10 (2:1).

Table 2. Highest rate of weight loss temperature and derivative weight of cyanate ester (B10)-cured epoxy resin.

\begin{tabular}{|c|c|c|c|}
\hline Cured Epoxy & Epoxy:B10 Ratio & $\begin{array}{c}\text { Highest Rate of } \\
\text { Weight Loss Temp }\left({ }^{\circ} \mathrm{C}\right)\end{array}$ & $\begin{array}{l}\text { Deriv. Weight at the } \\
\text { Highest Rate of Weight } \\
\text { Loss Temp }\left(\% /{ }^{\circ} \mathrm{C}\right)\end{array}$ \\
\hline $\mathrm{BP} *$ & \multirow{3}{*}{$2: 1$} & 414.3 & 0.93 \\
\hline $\mathrm{BP}$ & & 400.7 & 0.68 \\
\hline DGEBA & & 418.5 & 1.57 \\
\hline $\mathrm{BP}$ & \multirow{2}{*}{ 1:1 } & 392.2 & 0.77 \\
\hline DGEBA & & 394.3 & 1.40 \\
\hline
\end{tabular}

From Figure 4a, it can be seen that anisotropic BP/B10 (2:1) had a higher decomposition residue than $\mathrm{BP} / \mathrm{B} 10$ (1:1), which was due to the fact that there were more ordered rigid-rod structures in anisotropic BP/B10 (2:1) and it did not crack easily at high temperatures. The more LC phase in the sample, the more residue at high temperatures, as can also be seen in the literature [39]. In anisotropic BP/B10 (2:1), the fastest decomposition rate was larger, because BP/B10 (1:1) had more cyanate resin, and it formed a denser network structure (Table 2).

It is speculated that because anisotropic BP/B10 (2:1) had a longer curing time and had time to form a more stable network structure, the $5 \%$ weight loss temperature and the amount of decomposition residue are higher. The DGEBA molecular chain was relatively soft, although it was easy to move and crosslink, and the network structure was dense, but it was easier to break and crack at high temperatures, so the fastest cracking rate was higher, and the rigid-rod chain structure of the BP system was less easy to crack into small molecules.

\subsection{DMA Analysis}

DMA has been widely used to test the phenomenon of molecular motion in materials. Since thermoset epoxy resin will form a three-dimensional cross-linked network structure, molecular motion is restricted, so the degree of cross-linking will affect the polymer. Therefore, Nilsen [48] proposed the empirical equation of glass transition temperature (Tg) and crosslinking density $\left(1 / \bar{M}_{\mathcal{C}}\right)$ :

$$
\mathrm{T}_{\mathrm{g}}-\mathrm{T}_{\mathrm{g}}^{0} \cong \frac{3.9 \times 10^{4}}{\bar{M}_{\mathcal{c}}}
$$

where, $\bar{M}_{\mathcal{C}}$ : the average molecular weight between the two cross-linking points, $\mathrm{Tg}^{0}$ : glass transition temperature of un-crosslinked polymer and Tg: glass transition temperature of crosslinked polymer.

The Equation (1) can be used to illustrate the relationship between Tg and crosslinking density, that is, the larger the crosslinking density of the network structure, the higher the $\mathrm{Tg}$.

It can be seen from Table 3 and Figure 5a-c, that anisotropic BP/B10 (2:1) had a higher $\mathrm{Tg}, \tan \delta$ was the lowest and the structure was the hardest. Due to its longer curing time at LC phase temperature of BP, it formed a relatively stable network structure, so higher 
modulus was stored at a higher temperature and $\mathrm{Tg}$ was higher. The results of normal $\mathrm{BP} / \mathrm{B} 10$ and DGEBA/B10 systems agreed with our previous work [45]. For the same reason, the Tg of the $\mathrm{BP} / \mathrm{B} 10$ (1:1) sample was also higher than that of DGEBA/B10 (1:1), and the network structure was also harder, as seen in Figure 5b. The Tg of anisotropic BP/B10 (2:1) was only $12.9^{\circ} \mathrm{C}$ lower than anisotropic BP/DDS (1:1) [46], although the curing temperature of anisotropic BP/DDS (1:1) was much higher. The Tg of anisotropic $\mathrm{BP} / \mathrm{SAA}(1: 1)$ [20] was $29^{\circ} \mathrm{C}$ higher than anisotropic BP/B10 (2:1) but $34^{\circ} \mathrm{C}$ lower than $\mathrm{BP} / \mathrm{B} 10$ (1:1), because more curing agent was provided in the BP/B10 system and cured at the LC temperature to improve crosslinking density and structure, thereby obtaining a better Tg.

Table 3. Glass transition temperature of cured epoxy resin.

\begin{tabular}{ccc}
\hline Cured Epoxy & Epoxy:B10 Ratio & Peak Value of DMA's $\tan \delta\left(\mathbf{T g},{ }^{\circ} \mathbf{C}\right)$ \\
\hline BP ${ }^{*}$ & & 190 \\
\cline { 3 - 3 } BP & $2: 1$ & 183 \\
\hline DGEBA & & 184 \\
\hline BP & $1: 1$ & 253 \\
\hline DGEBA & & 223 \\
\hline$*^{*}$ Anisotropic. & &
\end{tabular}
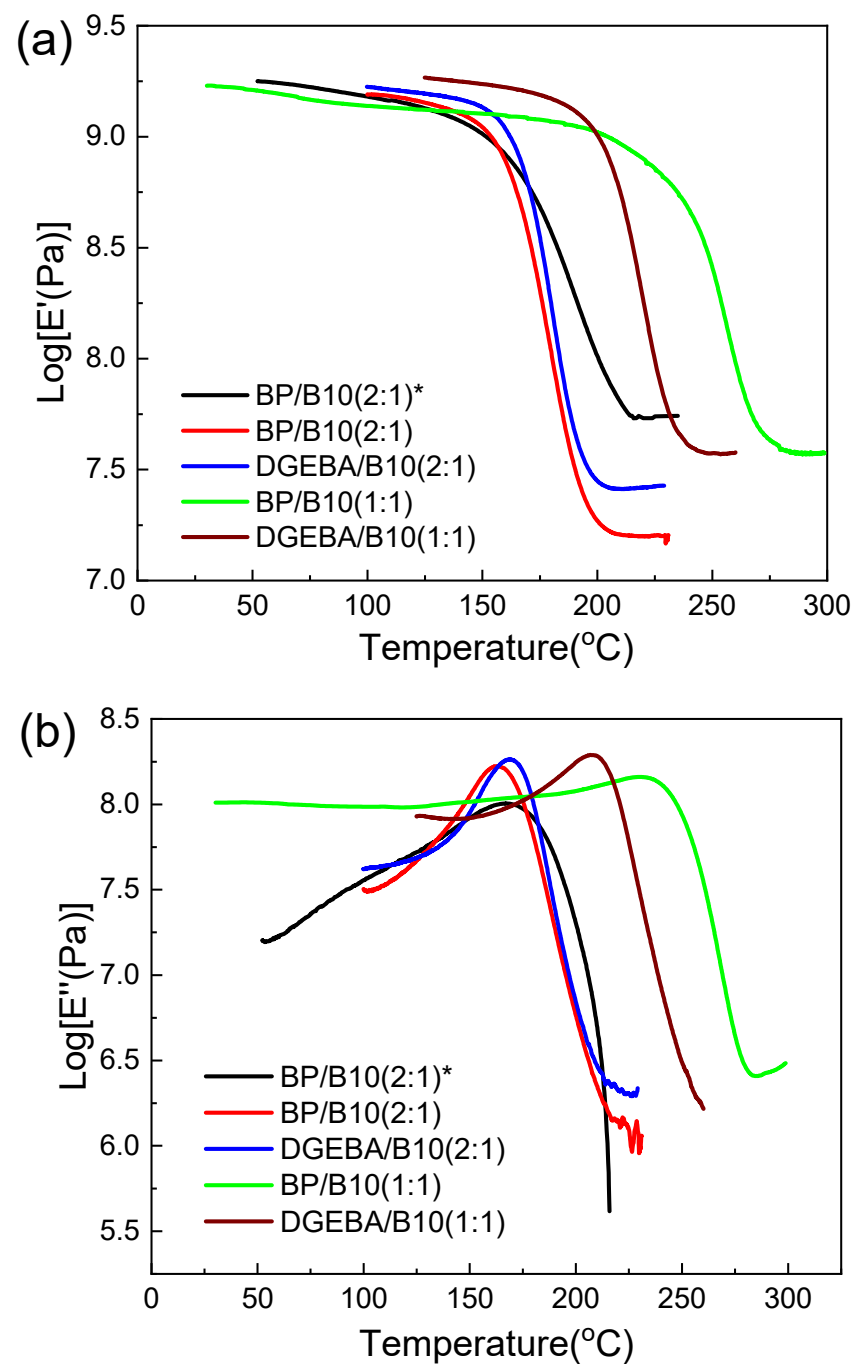

Figure 5. Cont. 


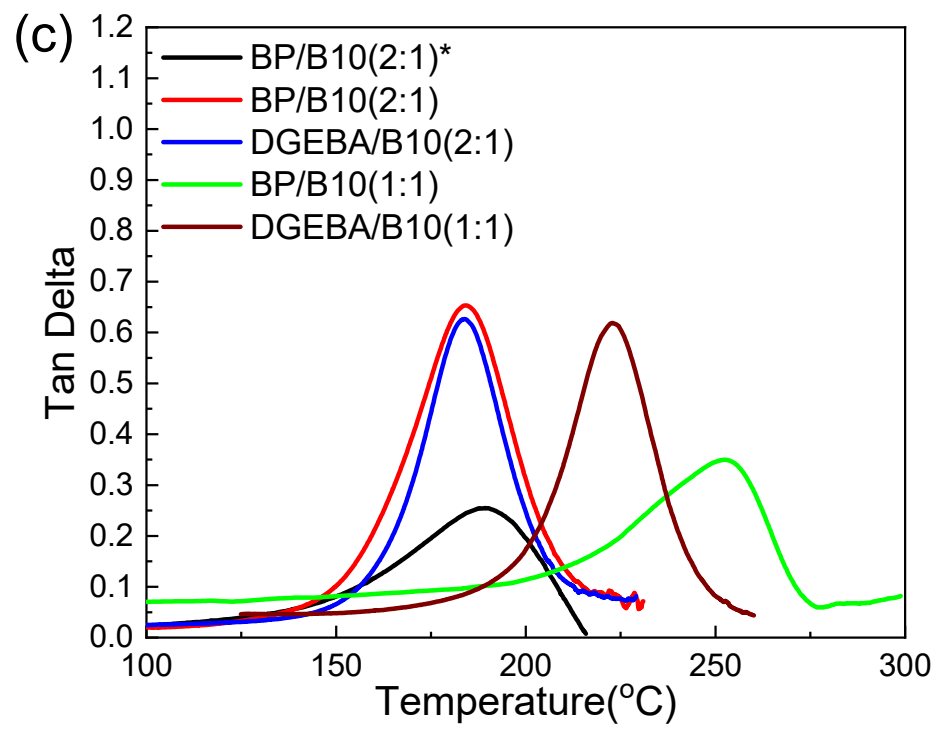

Figure 5. (a) Dynamic mechanical analysis (storage modulus), (b) dynamic mechanical analysis (loss modulus) and (c) dynamic mechanical analysis (tan delta) of cyanate ester (B10)-cured epoxy resin in epoxy:B10 = 2:1 (*: anisotropic).

\subsection{TMA Analysis}

For thermosetting epoxy resin processability, dimensional stability is very important. Good dimensional stability means that the product is not easily deformed and damaged by external forces. This experiment used TMA to detect the coefficient of thermal expansion (CTE) of rigid-rod epoxy resin after curing, and compared it with the commercial DGEBA.

Table 4 shows the CTE of the crosslinked structures of epoxy resin and cyanate ester after curing. They respectively represent the CTE of different crosslinked structures from $50{ }^{\circ} \mathrm{C}$ to $\mathrm{Tg}(\alpha 1)$ and higher than $\mathrm{Tg}$, to about $50{ }^{\circ} \mathrm{C}$ above $\mathrm{Tg}(\alpha 2)$.

Table 4. Tg and thermal expansion coefficients of cyanate ester-cured resin.

\begin{tabular}{|c|c|c|c|c|}
\hline \multirow{2}{*}{ Cured Epoxy } & \multirow{2}{*}{ Epoxy:B10 Ratio } & \multirow{2}{*}{$\operatorname{Tg}\left({ }^{\circ} \mathrm{C}\right)$} & \multicolumn{2}{|c|}{ CTE $\left(\mu \mathrm{m} / \mathrm{m}^{\circ} \mathrm{C}\right)$} \\
\hline & & & $\alpha 1$ & $\alpha 2$ \\
\hline $\mathrm{BP} *$ & \multirow{3}{*}{$2: 1$} & 174.2 & 60.6 & 150 \\
\hline $\mathrm{BP}$ & & 179.5 & 80.0 & 218 \\
\hline DGEBA & & 149.8 & 65.4 & 171 \\
\hline $\mathrm{BP}$ & \multirow{2}{*}{$1: 1$} & 197.3 & 73.8 & 182 \\
\hline DGEBA & & 202.5 & 85.9 & 134 \\
\hline
\end{tabular}

As seen from Table 4 and Figure 6, the anisotropic BP/B10 (2:1) had smaller values of $\alpha 1$ and $\alpha 2$, which suggests the existence of a more stable ordered LC structure and better dimensional stability. $\alpha 1$ and $\alpha 2$ of BP/B10 (2:1) were larger than DGEBA/B10 (1:1), because of the lack of a curing agent and the formation of a looser network. It can be seen that $\alpha 1$ of BP/B10 (1:1) was smaller than DGEBA/B10 (1:1), because the rigid-rod-like structure was not easy to move before $\mathrm{Tg}$. The $\alpha 2$ of BP/B10 (1:1) was relatively large, because $\mathrm{BP}$ was easier to move after $\mathrm{Tg}$, since it cured at lower temperatures for longer. The Tg of anisotropic BP/SAA (1:1) [20] was $200^{\circ} \mathrm{C}$, which was higher than anisotropic BP/B10 (2:1) but close to BP/B10 (1:1). The $\alpha 1$ and $\alpha 2$ of anisotropic BP/SAA (1:1) were 20.76 and 183.19. The $\alpha 2$ of anisotropic BP/B10 (2:1) was smaller than anisotropic BP/SAA (1:1), which demonstrated that the LC phase in anisotropic BP/B10 (2:1) provided a more stable structure than anisotropic BP/SAA (1:1) after Tg. 


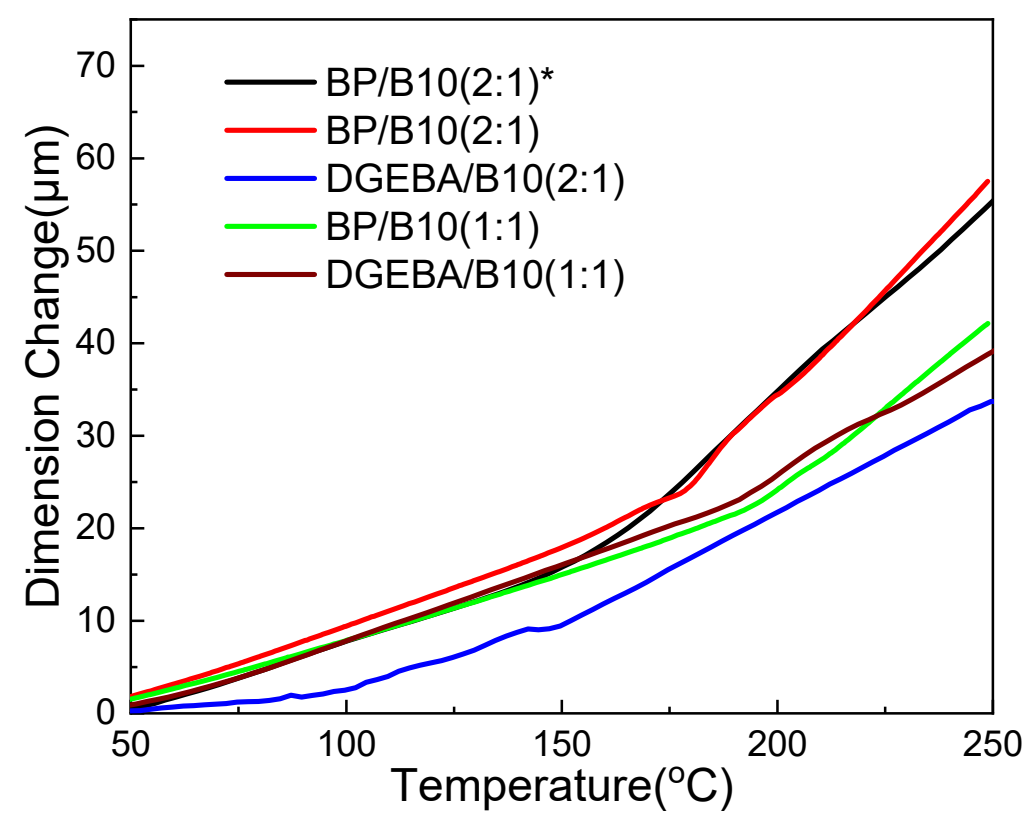

Figure 6. Thermal mechanical analysis of epoxy (*: anisotropic).

\subsection{DEA Analysis}

The dielectric constant could be reduced by the decrease in the dipole polarization in more highly crosslinked systems. The dielectric constant of the materials reduces with the increasing frequency when the frequency is lower than $10^{4} \mathrm{~Hz}$. This is because the dipoles of the materials can keep up with the change of electric field at low frequency and the remaining polarization is strong [49].

The dielectric loss factor is also correlated to the crosslinking density from its effect on the lagging of dipole polarization. The dielectric loss of the materials increases with the increasing frequency $\left(10^{2}-10^{6} \mathrm{~Hz}\right)$, and shows a maximum in the range of $10^{4}-10^{5} \mathrm{~Hz}$. Due to the effect of internal viscous and friction forces, the dipole polarization will absorb lots of electric field energy and transfer it to heat, resulting in an increase in dielectric loss [50]. When the electric field frequency increases, the electric field energy consumed by dipole polarization also rapidly increases [51,52]. Therefore, the dielectric loss increases as the frequency of the electric field increases. However, as with the dependence of the dielectric constant on the frequency of the electric field, if the frequency of the electric field is high enough $\left(>10^{5} \mathrm{~Hz}\right)$, the dipoles inside the material will maintain the relaxation process because they do not have enough time to establish polarization. In this case, the electric field energy consumed to overcome internal viscous and frictional forces is reduced, and this change is manifested as a reduction in dielectric loss [52-54].

As seen from Tables 5-7, and Figure 7a-c, the dielectric constant of anisotropic BP/B10 (2:1) was lower than that of BP/B10 (2:1), but it was higher than that of DGEBA/B10 (2:1), and the loss factor was the same. This is because the ratio of 2:1 leads to less curing agent. The BP system was more difficult to crosslink and had more linear chains, while the DGEBA system had a softer molecular chain, although there was less curing agent. However, it was easy to move and crosslink, and the degree of crosslinking was higher, so it had better dielectric properties than the BP system. 
Table 5. Permittivity and loss factor of cured resin at 10, 100, 1000 and 10,000 Hz, and $-150,30$ and $150{ }^{\circ} \mathrm{C}$, at BP:B10 = 2:1 (anisotropic).

\begin{tabular}{cccc}
\hline Frequency $\mathbf{( H z )}$ & Temperature $\left({ }^{\circ} \mathbf{C}\right)$ & Permittivity & Loss Factor \\
\hline \multirow{2}{*}{10} & -125 & 2.597 & 0.012 \\
\cline { 2 - 4 } & 30 & 3.707 & 0.263 \\
\cline { 2 - 4 } & 150 & 3.497 & 0.620 \\
\cline { 2 - 4 } 100 & -125 & 2.575 & 0.009 \\
\cline { 2 - 4 } & 30 & 3.451 & 0.088 \\
\hline \multirow{2}{*}{1000} & 150 & 3.252 & 0.141 \\
& -125 & 2.555 & 0.010 \\
\hline \multirow{2}{*}{10,000} & 30 & 3.374 & 0.054 \\
\hline & 150 & 3.150 & 0.060 \\
\hline & -125 & 2.465 & 0.009 \\
\hline & 30 & 3.334 & 0.066 \\
\hline
\end{tabular}

Table 6. Permittivity and loss factor of cured resin at 10,100, 1000 and 10,000 Hz, and -150, 30 and $150{ }^{\circ} \mathrm{C}$, at BP:B10 = 2:1.

\begin{tabular}{cccc}
\hline Frequency (Hz) & Temperature $\left({ }^{\circ} \mathbf{C}\right)$ & Permittivity & Loss Factor \\
\hline \multirow{2}{*}{10} & -125 & 2.929 & 0.024 \\
\cline { 2 - 4 } & 30 & 3.826 & 0.064 \\
\cline { 2 - 4 } 100 & 150 & 4.819 & 0.016 \\
\cline { 2 - 4 } & -125 & 2.903 & 0.613 \\
\cline { 2 - 4 } & 30 & 3.781 & 0.045 \\
\cline { 2 - 4 } 1000 & 150 & 3.929 & 0.013 \\
& -125 & 2.884 & 0.110 \\
\hline \multirow{2}{*}{10,000} & 30 & 3.728 & 0.033 \\
\hline & 150 & 3.749 & 0.012 \\
\hline & -125 & 2.811 & 0.046 \\
\hline & 30 & 3.602 & 0.029 \\
\hline
\end{tabular}

Table 7. Permittivity and loss factor of cured resin at 10,100, 1000 and 10,000 Hz, and -150, 30 and $150{ }^{\circ} \mathrm{C}$ at DGEBA:B10 $=2: 1$.

\begin{tabular}{cccc}
\hline Frequency $\mathbf{( H z )}$ & Temperature $\left({ }^{\circ} \mathbf{C}\right)$ & Permittivity & Loss Factor \\
\hline \multirow{2}{*}{10} & -125 & 2.837 & 0.028 \\
\cline { 2 - 4 } & 30 & 3.172 & 0.020 \\
\cline { 2 - 4 } & 150 & 4.037 & 1.856 \\
\hline \multirow{2}{*}{100} & -125 & 2.797 & 0.024 \\
\cline { 2 - 4 } & 30 & 3.155 & 0.013 \\
\hline
\end{tabular}


Table 7. Cont.

\begin{tabular}{cccc}
\hline Frequency (Hz) & Temperature $\left({ }^{\circ} \mathbf{C}\right)$ & Permittivity & Loss Factor \\
\hline \multirow{2}{*}{1000} & -125 & 2.765 & 0.023 \\
\cline { 2 - 4 } & 30 & 3.142 & 0.010 \\
\cline { 2 - 4 } 10,000 & 150 & 3.312 & 0.074 \\
\cline { 2 - 4 } & -125 & 2.072 & 0.018 \\
\hline \multirow{2}{*}{10} & 3.051 & 0.011 \\
\hline & 150 & 3.184 & 0.032 \\
\hline
\end{tabular}
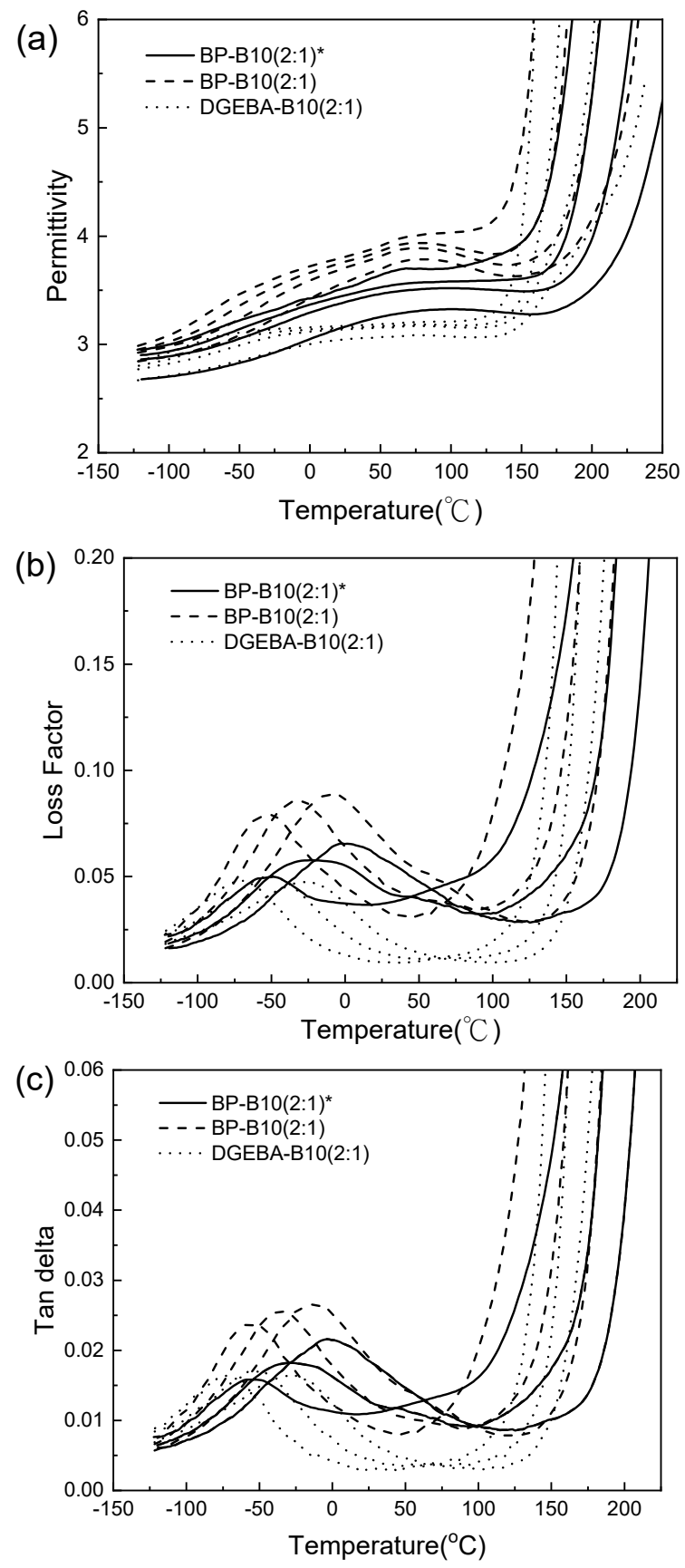

Figure 7. (a) Permittivity, (b) loss factor and (c) tan delta of cyanate ester (B10)-cured epoxy at 100, 1000 and 10,000 Hz (curves from left to right) (*: anisotropic). 
The lower $\beta$ relaxation temperature of DGEBA/B10 means that only lower energy was required to move its short segments because of the softer structure of DGEBA. The $\beta$ relaxation temperatures of the anisotropic BP/B10 (2:1) and BP/B10 (2:1) were slightly higher, which means that higher energy was required to move their short segments. This is because the BP structure was harder. The $\alpha$ relaxation of the BP/B10 and DGEBA/B10 systems was very large, which may be due to trapping of the main chain of small molecules that moved first.

From Tables 8 and 9, and Figure $8 \mathrm{a}-\mathrm{C}$, it is seen that BP/B10 (1:1) had a lower dielectric constant and loss coefficient than DGEBA/B10 (1:1). This is because the ratio of 1:1 provided enough curing agent, $\mathrm{BP} / \mathrm{B} 10$ was easy to form a network structure and its dipole moment was not easy to move after formation, so the dielectric properties were better than DGEAB/B10. The anisotropic BP/B10 (2:1) and BP/B10 (1:1) showed better dielectric constant and dielectric loss than the report of DGEBA/B10 (1:1) [31]. BP/B10 (1:1) also had better dielectric properties than TMBP/B10 (2:1) and TMBP/B10 (1:1) [18], as well as DGEBA/B10 [52,55].

Table 8. Permittivity and loss factor of cured resin at 10, 100, 1000 and 10,000 Hz, and $-125,30$ and $150{ }^{\circ} \mathrm{C}$ at $\mathrm{BP}: \mathrm{B} 10=1: 1$.

\begin{tabular}{cccc}
\hline Frequency $\mathbf{( H z )}$ & Temperature $\left({ }^{\circ} \mathbf{C}\right)$ & Permittivity & Loss Factor \\
\hline \multirow{3}{*}{10} & -125 & 2.548 & 0.005 \\
\cline { 2 - 4 } & 30 & 2.821 & 0.020 \\
\cline { 2 - 4 } & 150 & 2.833 & 0.040 \\
\cline { 2 - 4 } 100 & -125 & 2.525 & 0.284 \\
\cline { 2 - 4 } & 30 & 2.812 & 0.011 \\
\hline \multirow{3}{*}{1000} & 150 & 2.814 & 0.006 \\
& -125 & 2.505 & 0.044 \\
& 30 & 2.795 & 0.002 \\
\hline \multirow{3}{*}{10,000} & 150 & 2.802 & 0.004 \\
& -125 & 2.362 & 0.009 \\
& 30 & 2.638 & 0.001 \\
\hline & 150 & 2.665 & 0.040 \\
\hline
\end{tabular}

Table 9. Permittivity and loss factor of cured resin at 10, 100, 1000 and 10,000 Hz, and $-125,30$ and $150{ }^{\circ} \mathrm{C}$ in DGEBA:B10 = 1:1.

\begin{tabular}{cccc}
\hline Frequency (Hz) & Temperature $\left({ }^{\circ} \mathbf{C}\right)$ & Permittivity & Loss Factor \\
\hline \multirow{3}{*}{10} & -125 & 2.802 & 0.016 \\
\cline { 2 - 4 } & 30 & 3.064 & 0.008 \\
\cline { 2 - 4 } 100 & 150 & 3.075 & 0.035 \\
\cline { 2 - 4 } & -125 & 2.757 & 0.014 \\
\cline { 2 - 4 } & 30 & 3.048 & 0.011 \\
\hline \multirow{2}{*}{1000} & 150 & 3.052 & 0.013 \\
& -125 & 2.756 & 0.014 \\
\cline { 2 - 4 } & 30 & 3.031 & 0.015 \\
\hline \multirow{2}{*}{10,000} & 150 & 3.038 & 0.011 \\
& -125 & 2.652 & 0.014 \\
\hline & 30 & 2.943 & 0.020 \\
\hline & 150 & 2.963 & 0.008 \\
\hline
\end{tabular}



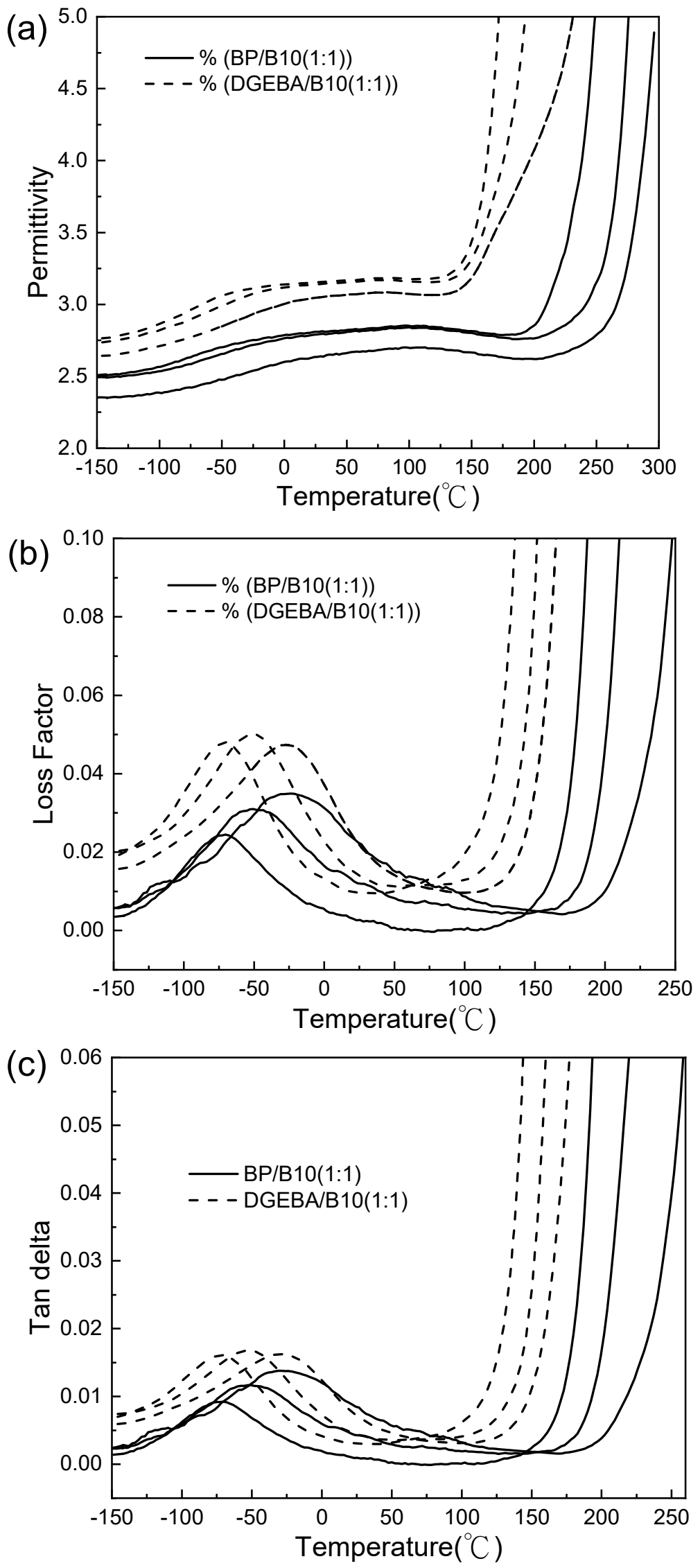

Figure 8. (a) Permittivity, (b) loss factor and (c) tan delta of cyanate ester (B10)-cured epoxy at 100, 1000 and 10,000 $\mathrm{Hz}$ (curves from left to right). 
The plots of the dielectric loss vs. frequency were used to obtain the peak temperature and the corresponding frequency, as shown in Table 10. Plots of the logarithm of the frequency vs. the reciprocal of the temperature (log f vs. 1000/Tmax), and the apparent activation energy after linear regression, were obtained, as shown in Table 11 . The activation energy of anisotropic BP/B10 (2:1) was higher than that of BP/B10 (2:1) and DGEBA/B10 (2:1). The activation energy of BP/B10 (1:1) was higher than that of DGEBA/B10 (1:1), but the activation energy of BP/B10 (1:1) was lower than that of anisotropic BP/B10 (2:1). Since the curing time of anisotropic BP/B10 (2:1) and BP/B10 (1:1) was longer, and anisotropic $\mathrm{BP} / \mathrm{B} 10$ (2:1) may contain a LC phase after curing, higher energy of the side chain is required to move.

Table 10. Sub-glass transition temperature of cyanate ester-cured epoxy resin at 2:1 and 1:1 at different frequencies.

\begin{tabular}{ccccc}
\hline Cured Epoxy & $\mathbf{1 0 ~ H z}$ & $\mathbf{1 0 0 ~ H z}$ & $\mathbf{1 0 0 0 ~} \mathbf{~ z z}$ & $\mathbf{1 0 , 0 0 0 ~} \mathbf{~ z z}$ \\
\hline BP/B10 (2:1) & -85.08 & -55.45 & -23.64 & 1.57 \\
\hline BP/B10 (2:1) & -70.09 & -50.19 & -34.27 & -6.44 \\
\hline DGEBA/B10 (2:1) & -82.29 & -70.20 & -49.95 & -29.58 \\
\hline BP/B10 (1:1) & -87.74 & -70.35 & -50.60 & -21.05 \\
\hline DGEBA/B10 (1:1) & -77.79 & -61.95 & -41.80 & -21.89 \\
*: Anisotropic. & & & &
\end{tabular}

Table 11. Apparent activation energy of cyanate ester-cured epoxy resin.

\begin{tabular}{cc}
\hline Cured Epoxy & Apparent Activation Energy (KJ/mol) \\
\hline BP/B10 (2:1) * & 61.78 \\
\hline BP/B10 (2:1) & 44.54 \\
\hline DGEBA/B10 (2:1) & 42.33 \\
\hline BP/B10 (1:1) & 51.88 \\
\hline DGEBA/B10 (1:1) & 42.17 \\
\hline : Anisotropic. &
\end{tabular}

\section{Conclusions}

The thermal properties, including thermal gravimetric properties, dynamic mechanical properties and thermal expansion coefficient, and the dielectric properties of rigid-rod epoxy (BP) and commercial DGEBA epoxy, cured with cyanate ester (B10) as a curing agent, were studied. In terms of the thermal decomposition properties, anisotropic BP/B10 (2:1) had the highest 5\% weight loss temperature and the highest amount of residue. DGEBA/B10 cracking residue was low, and the fastest cracking rate was large. Since anisotropic BP/B10 (2:1) had a longer curing time, it had time to form a more stable ordered network structure, and the BP rigid-rod chain structure was less likely to be broken into small molecules. With respect to the dynamic mechanical analysis, anisotropic BP/B10 (2:1) and BP/B10 (1:1) had higher Tg and harder network structure than other samples. Due to the long curing time at LC phase temperature, the BP system formed a relatively stable network structure, and its rigid-rod chain structure was not as soft as DGEBA. From dimensional stability analysis, anisotropic BP/B10 (2:1) had smaller $\alpha 1$ and $\alpha 2$, which suggests a more stable network structure and better dimensional stability. From dielectric analysis, the dielectric constant of anisotropic BP/B10 (2:1) was lower than that of BP/B10 (2:1), but higher than that of DGEBA/B10 (2:1) because there was less curing agent and the BP system was harder and more difficult to crosslink, while the DGEBA system had a softer molecular chain with more straight chains. Although DGEBA had less curing agent, it was easy to move and crosslink and had a higher degree of crosslinking, so it had better dielectric properties than the BP system. BP/B10 (1:1) had a lower dielectric constant 
than DGEBA/B10 (1:1). Since there was enough curing agent, BP/B10 was easy to form an isocyanurate network structure, curing time was long and its dipole moment was not easy to move after formation, so the dielectric properties were better than DGEBA/B10. The anisotropic BP/B10 system had better thermal properties than the commercial epoxy with flexible structure. BP/B10 also demonstrated better dielectric properties than the commercial epoxy resin when enough curing agent was provided.

Author Contributions: Conceptualization, C.-P.L.; methodology, C.-P.L.; validation, C.-P.L.; formal analysis, C.-P.L.; investigation, C.-P.L.; data curation, C.-P.L. and C.-M.C.; writing-original draft preparation, C.-P.L.; writing — review and editing, C.-P.L.; visualization, C.-P.L.; funding acquisition, C.-P.L. All authors have read and agreed to the published version of the manuscript.

Funding: This research was funded by the Ministry of Science and Technology of Taiwan with grant program code MOST 108-2218-E-239-003.

Conflicts of Interest: The authors declare no conflict of interest.

\section{References}

1. Gu, J.; Liang, C.; Zhao, X.; Gan, B.; Qiu, H.; Guo, Y.; Yang, X.; Zhang, Q.; Wang, D.Y. Highly thermally conductive flame-retardant epoxy nanocomposites with reduced ignitability and excellent electrical conductivities. Compos. Sci. Technol. 2017, 139, 83-89. [CrossRef]

2. Wang, T.; Wang, J.; Huo, S.; Zhang, B.; Yang, S. Preparation and flame retardancy of DOPO-based epoxy resin containing bismaleimide. High Perform. Polym. 2016, 28, 1090-1095. [CrossRef]

3. Gong, Y.; Zhou, W.; Sui, X.; Kou, Y.; Xu, L.; Cai, H.; Liu, X.; Chen, Q. Mechanical and dielectric properties of epoxy composites filled with hybrid aluminum particles with binary size distribution. High Perform. Polym. 2019, 31, 124-134. [CrossRef]

4. Yang, S.; Wang, J.; Huo, S.; Wang, J.; Tang, Y. Synthesis of a phosphorus/nitrogen-containing compound based on maleimide and cyclotriphosphazene and its flame-retardant mechanism on epoxy resin. Polym. Degrad. Stab. 2016, 126, 9-16. [CrossRef]

5. da Silva, T.T.; da Silveira, P.H.P.M.; Ribeiro, M.P.; Lemos, M.F.; da Silva, A.P.; Monteiro, S.N.; Nascimento, L.F.C. Thermal and Chemical Characterization of Kenaf Fiber (Hibiscus cannabinus) Reinforced Epoxy Matrix Composites. Polymers 2021, 13, 2016. [CrossRef] [PubMed]

6. Farooq, U.; Ali, M.U.; Hussain, S.J.; Ahmad, M.S.; Zafar, A.; Ghafoor, U.; Subhani, T. Improved Ablative Properties of Nanodiamond-Reinforced Carbon Fiber-Epoxy Matrix Composites. Polymers 2021, 13, 2035. [CrossRef] [PubMed]

7. Yang, S.; Zhang, Q.; Hu, Y. Synthesis of a Novel Flame Retardant Containing Phosphorus, Nitrogen and Boron and Its Application in Flame-Retardant Epoxy Resin; Elsevier: Amsterdam, The Netherlands, 2016; Volume 133, ISBN 8627876517.

8. Morkavuk, S.; Köklü, U.; Bağc1, M.; Gemi, L. Cryogenic machining of carbon fiber reinforced plastic (CFRP) composites and the effects of cryogenic treatment on tensile properties: A comparative study. Compos. Part B Eng. 2018, 147, 1-11. [CrossRef]

9. Barra, G.; Guadagno, L.; Vertuccio, L.; Simonet, B.; Santos, B.; Zarrelli, M.; Arena, M.; Viscardi, M. Different methods of dispersing carbon nanotubes in epoxy resin and initial evaluation of the obtained nanocomposite as a matrix of carbon fiber reinforced laminate in terms of vibroacoustic performance and flammability. Materials 2019, 12, 2998. [CrossRef]

10. Barra, G.; Vertuccio, L.; Naddeo, C.; Arena, M.; Viscardi, M.; Guadagno, L. Thermal degradation and fire properties of epoxy modified resins. AIP Conf. Proc. 2018, 1981, 20149.

11. Kumar, S.; Krishnan, S.; Samal, S.K.; Mohanty, S.; Nayak, S.K. Toughening of Petroleum Based (DGEBA) Epoxy Resins with Various Renewable Resources Based Flexible Chains for High Performance Applications: A Review. Ind. Eng. Chem. Res. 2018, 57, 2711-2726. [CrossRef]

12. Shirude, S.R.; Shambharkar, S.Y.; Bhosale, H.B.; Patil, V.U.; Patil, A.G. A Survey on Epoxy Resins. Int. J. Innov. Res. Sci. Eng. Technol. ISO 2007, 3297, 14861-14867.

13. Su, W.F.; Huang, H.W.; Pan, W.P. Thermal properties of rigid rod epoxies cured with diaminodiphenylsulfone and dicyandiamide. Thermochim. Acta 2002, 392, 391-394. [CrossRef]

14. Su, W.F.A.; Schoch, K.F.; Smith, J.D.B. Comparison of cure conditions for rigid rod epoxy and bisphenol A epoxy using thermomechanical analysis. J. Appl. Polym. Sci. 1998, 70, 2163-2167. [CrossRef]

15. Zhang, Q.; Chen, G.; Wu, K.; Shi, J.; Liang, L.; Lu, M. Biphenyl liquid crystal epoxy containing flexible chain: Synthesis and thermal properties. J. Appl. Polym. Sci. 2020, 137, 49143. [CrossRef]

16. Yang, X.; Zhong, X.; Zhang, J.; Gu, J. Intrinsic high thermal conductive liquid crystal epoxy film simultaneously combining with excellent intrinsic self-healing performance. J. Mater. Sci. Technol. 2021, 68, 209-215. [CrossRef]

17. Yang, X.; Zhu, J.; Yang, D.; Zhang, J.; Guo, Y.; Zhong, X.; Kong, J.; Gu, J. High-efficiency improvement of thermal conductivities for epoxy composites from synthesized liquid crystal epoxy followed by doping BN fillers. Compos. Part B Eng. 2020, 185, 107784. [CrossRef]

18. Su, W.A. Thermoplastic and thermoset main chain liquid crystal polymers prepared from biphenyl mesogen. J. Polym. Sci. Part A Polym. Chem. 1993, 31, 3251-3256. [CrossRef] 
19. Su, W.F.; Fu, Y.C.; Pan, W.P. Thermal properties of high refractive index epoxy resin system. Thermochim. Acta 2002, 392-393, 385-389. [CrossRef]

20. Su, W.F.A.; Chen, K.C.; Tseng, S.Y. Effects of chemical structure changes on thermal, mechanical, and crystalline properties of rigid rod epoxy resins. J. Appl. Polym. Sci. 2000, 78, 446-451. [CrossRef]

21. Zeng, L.; Liang, G.; Gu, A.; Yuan, L.; Zhuo, D.; Hu, J.T. High performance hybrids based on a novel incompletely condensed polyhedral oligomeric silsesquioxane and bismaleimide resin with improved thermal and dielectric properties. J. Mater. Sci. 2012, 47, 2548-2558. [CrossRef]

22. Goertzen, W.K.; Kessler, M.R. Thermal and mechanical evaluation of cyanate ester composites with low-temperature processability. Compos. Part A Appl. Sci. Manuf. 2007, 38, 779-784. [CrossRef]

23. Crawford, A.O.; Howlin, B.J.; Cavalli, G.; Hamerton, I. Examining the thermo-mechanical properties of novel cyanate ester blends through empirical measurement and simulation. React. Funct. Polym. 2012, 72, 596-605. [CrossRef]

24. Yan, H.Q.; Chen, S.; Qi, G.R. Synthesis, cure kinetics and thermal properties of the 2,7- dihydroxynaphthalene dicyanate. Polymer 2003, 44, 7861-7867. [CrossRef]

25. Tang, Y.; Xu, S.; Xie, Y.; Gu, J.; Song, Z.; Gao, F.; Kong, J. Interfacial RAFT polymerization induced ultra low dielectric loss ceramic/cyanate ester composites. Compos. Sci. Technol. 2016, 124, 10-16. [CrossRef]

26. Wu, G.; Cheng, Y.; Wang, K.; Wang, Y.; Feng, A. Fabrication and characterization of OMMt/BMI/CE composites with low dielectric properties and high thermal stability for electronic packaging. J. Mater. Sci. Mater. Electron. 2016, 27, 5592-5599. [CrossRef]

27. Venkatesh, M.; Gouthaman, S.; Kanemoto, S.O.; Lakshmi, M.S.; Hamerton, I. Development of epoxy-cyanate ester-clay nanocomposites offering enhanced thermally stability. J. Appl. Polym. Sci. 2019, 136, 47754. [CrossRef]

28. Kim, B.S. Effect of cyanate ester on the cure behavior and thermal stability of epoxy resin. J. Appl. Polym. Sci. 1997, 65, 85-90. [CrossRef]

29. Ren, F.; Zhu, G.; Ren, P.; Wang, Y.; Cui, X. In situ polymerization of graphene oxide and cyanate ester-epoxy with enhanced mechanical and thermal properties. Appl. Surf. Sci. 2014, 316, 549-557. [CrossRef]

30. Chen, Y.; Li, Z.; Liu, Y.; Teng, C.; Cui, W. Curing Mechanism and Mechanical Properties of Al2O3/Cyanate Ester-Epoxy Composites. J. Electron. Mater. 2020, 49, 1473-1481. [CrossRef]

31. Lei, Y.; Xu, M.; Jiang, M.; Huang, Y.; Liu, X. Curing behaviors of cyanate ester/epoxy copolymers and their dielectric properties. High Perform. Polym. 2017, 29, 1175-1184. [CrossRef]

32. Hwang, H.J.; Hsu, S.W.; Chung, C.L.; Wang, C.S. Low dielectric epoxy resins from dicyclopentadiene-containing poly(phenylene oxide) novolac cured with dicyclopentadiene containing epoxy. React. Funct. Polym. 2008, 68, 1185-1193. [CrossRef]

33. Hwang, H.J.; Wang, C.S. Thermal behavior and properties of naphthalene containing bismaleimide-triazine resins. J. Appl. Polym. Sci. 1998, 68, 1199-1207. [CrossRef]

34. Lin, C.H. Synthesis of novel phosphorus-containing cyanate esters and their curing reaction with epoxy resin. Polymer 2004, 45, 7911-7926. [CrossRef]

35. Matsumura, S.; Hlil, A.R.; Lepiller, C.; Gaudet, J.; Guay, D.; Shi, Z.; Holdcroft, S.; Hay, A.S. Stability and Utility of Pyridyl Disulfide Functionality in RAFT and Conventional Radical Polymerizations. J. Polym. Sci. Part A Polym. Chem. 2008, 46, 7207-7224.

36. Krishnadevi, K.; Selvaraj, V. Biowaste material reinforced cyanate ester based epoxy composites for flame retardant applications. High Perform. Polym. 2015, 28, 881-894. [CrossRef]

37. Wu, F.; Tuan, C.C.; Song, B.; Moon, K.S.; Wong, C.P. Controlled synthesis and evaluation of cyanate ester/epoxy copolymer system for high temperature molding compounds. J. Polym. Sci. Part A Polym. Chem. 2018, 56, 1337-1345. [CrossRef]

38. Ariraman, M.; Sasikumar, R.; Alagar, M. Hybridization of PDMS based cyanate ester and DGEBA for radiation resistant and microelectronics applications. RSC Adv. 2015, 5, 63641-63649. [CrossRef]

39. Yang, Z.; Peng, H.; Wang, W.; Liu, T. Crystallization behavior of poly( $\varepsilon$-caprolactone)/layered double hydroxide nanocomposites. J. Appl. Polym. Sci. 2010, 116, 2658-2667. [CrossRef]

40. Liang, G.; Ren, P.; Zhang, Z.; Lu, T. Effect of the epoxy molecular weight on the properties of a cyanate ester/epoxy resin system. J. Appl. Polym. Sci. 2006, 101, 1744-1750. [CrossRef]

41. Chen, S.; Yuan, L.; Wang, Z.; Gu, A.; Liang, G. Self-constructed nanodomain structure in thermosetting blend based on the dynamic reactions of cyanate ester and epoxy resins and its related property. Compos. Part B 2019, 177, 107438. [CrossRef]

42. Wang, G.; Wang, R.; Fu, G.; Gao, T.; Fu, C.; Kuang, H.; Yang, F.; Jiao, W.; Hao, L.; Liu, W. Study on Phenolphthalein Poly ( ether sulfone ) -Modified Cyanate Ester Resin and Epoxy Resin Blends. Polym. Eng. Sci. 2015, 55, 2591-2602. [CrossRef]

43. Wang, C.S.; Lee, M.C. Synthesis, Characterization, and Properties of Multifunctional Naphthalene-Containing Epoxy Resins Cured with Cyanate Ester. J. Appl. Polym. Sci. 1999, 73, 1611-1622. [CrossRef]

44. Ho, T.H.; Hwang, H.J.; Shieh, J.Y.; Chung, M.C. Thermal, physical and flame-retardant properties of phosphorus-containing epoxy cured with cyanate ester. React. Funct. Polym. 2009, 69, 176-182. [CrossRef]

45. Su, W.A.; Chuang, C. Effects of Chemical Structure Changes on Curing Reactions and Thermal Properties of Cyanate Ester-Cured Rigid-Rod. J. Appl. Polym. Sci. 2002, 85, 2419-2422. [CrossRef]

46. Hsu, S.H.; Wu, M.C.; Chen, S.; Chuang, C.M.; Lin, S.H.; Su, W.F. Synthesis, morphology and physical properties of multi-walled carbon nanotube/biphenyl liquid crystalline epoxy composites. Carbon N. Y. 2012, 50, 896-905. [CrossRef] 
47. Shiota, A.; Ober, C.K. Analysis of smectic structure formation in liquid crystalline thermosets. Polymer 1997, $38,5857-5867$. [CrossRef]

48. Nielsen, L.E. Cross-Linking Effect on Physical Properties of Polymers. J. Macromol. Sci. Part C Polym. Rev. 2008, 3, 69-103. [CrossRef]

49. Wang, Y.; Kou, K.; Wu, G.; Feng, A.; Zhuo, L. The effect of bis allyl benzoxazine on the thermal, mechanical and dielectric properties of bismaleimide-cyanate blend polymers. RSC Adv. 2015, 5, 58821-58831. [CrossRef]

50. Chen, Y.; Guo, H.; Geng, C.; Wu, Y.; Dai, G.; Teng, C. Effect of poly(ether ether ketone) and allyl compounds on microstructure and properties of bismaleimide. J. Mater. Sci. Mater. Electron. 2019, 30, 991-1000. [CrossRef]

51. Wang, Y.; Kou, K.; Wu, G.; Zhuo, L.; Li, J.; Zhang, Y. The curing reaction of benzoxazine with bismaleimide/cyanate ester resin and the properties of the terpolymer. Polymer 2015, 77, 354-360. [CrossRef]

52. Chen, Y.; Li, Z.; Liu, Y.; Teng, C.; Cui, W. Effect of Al2O3 on microstructure and dielectric properties of epoxy-cyanate ester composite material. J. Mater. Sci. Mater. Electron. 2019, 30, 20614-20623. [CrossRef]

53. Wan, L.; Zhang, X.; Wu, G.; Feng, A. Thermal conductivity and dielectric properties of bismaleimide/cyanate ester copolymer. High Volt. 2017, 2, 167-171. [CrossRef]

54. Yu, J.; Huo, R.; Wu, C.; Wu, X.; Wang, G.; Jiang, P. Influence of interface structure on dielectric properties of epoxy/alumina nanocomposites. Macromol. Res. 2012, 20, 816-826. [CrossRef]

55. Zhou, J.; Jiang, Y.; Wu, G.; Wu, W.; Wang, Y.; Wu, K.; Cheng, Y. Investigation of dielectric and thermal conductive properties of epoxy resins modified by core-shell structured PS@SiO2. Compos. Part A Appl. Sci. Manuf. 2017, 97, 76-82. [CrossRef] 